\title{
Experimental analysis of the state of stress in a steel - titanium perforated plate loaded with concentrated force
}

\author{
Mateusz Marcin Konieczny, Henryk Achtelik, Grzegorz Gasiak \\ Opole University of Technology, Poland \\ mateuszmarcinkonieczny@wp.pl,kmpkm@po.edu.pl,g.gasiak@po.edu.pl
}

\begin{abstract}
The paper presents an experimental analysis of the state of stress, free supported on the edge of a steel - titanium circular perforated plate loaded with a centrally concentrated force, created in the technological process of explosion welding. For this purpose, a special test stand was designed and a methodology for testing the perforated plate was developed. Resistance strain gauges were used to measure the state of strain. The load was applied in the center of the plate to a pressure stamp. As a result of the research, the values of radial, circumferential and equivalent von Mises stress were obtained as a function of the radius of the plate perforation circle and its load. The stress distribution topography revealed the zones of maximum stress of the steel - titanium perforated plate. The proposed method of experimental research can be used by engineers to verify the state of stress, e.g. in the designed tube sheet walls of reactors for ammonia synthesis.
\end{abstract}

\section{open 2 Access}

Citation: Konieczny, M. M., N., Achtelik, H., Gasiak, G., Experimental analysis of the state of stress in a steel - titanium perforated plate loaded with concentrated force, Frattura ed Integrità Strutturale, 55 (2021) 277-288.

Received: 12.12 .2020

Accepted: 23.12.2020

Published: 01.01.2021

Copyright: (C) 2021 This is an open access article under the terms of the CC-BY 4.0, which permits unrestricted use, distribution, and reproduction in any medium, provided the original author and source are credited.

KEYWORDS. Perforated plate; Concentrated force; Stress analysis; Experimental research.

\section{INTRODUCTION}

I $\mathrm{n}$ the work of a designer, a frequent problem is the proper determination of the level of stresses and strains. Experimental tests are used to assess the correctness of the design of a given structure element in terms of its strength. The assessment is based on the material effort determined by the states of stress and strain. Research on these states can be carried out on real objects, as well as on their models made of various materials. On the basis of these tests, information is obtained that allows for a possible improvement of a structural element and for checking its behavior under operational loads [1].

In the literature, there are many works related to the analysis of the state of stress and strain in perforated plates $[2,3,4,5$, $6,7,8]$. An experimental verification of the mathematical model obtained in [9] is presented in [10], where the methodology of experimental tests was developed, which would allow to determine the value of stresses in perforated plates loaded centrally by concentrated force. The diameters of the holes, as well as the topography of their arrangement in the plate prepared for the tests, ensured the stability of the section weakening coefficients. Resistance strain gauges were placed between the holes to measure the strain. The axially symmetrical perforated plate has been bent with a concentrated force applied centrally. Additionally, plate bending was monitored with a dial gauge during deformation measurements. Based on the measured deformation values, the values of radial, circumferential and equivalent von Mises stresses in the plate were 
obtained. An experimental approach to the analysis of perforated plates was also proposed by the authors of [11], where they analyzed the state of stress and deflection of a circumferentially freely supported, circular-symmetric perforated plate, loaded with static pressure. For this purpose, a special test stand was designed and a methodology for testing the perforated plate was developed. The load on the perforated plate was carried out by means of a special elastic cushion, similar to that of Duncan [12]. Tensometric rosettes were used to measure the plate state of deformation. The load on the plate was determined by the deflection of its center. As a result of the research, the values of stresses were obtained as a function of the radius of the plate perforation circle and its load. In addition, the experimental approach related to the analysis of the state of deformation and stress in single-layer square perforated plates made of steel with specific geometric parameters was the subject of works $[13,14,15]$.

Currently, more and more often in engineering structures are used elements consisting of many layers and of many materials, i.e. plated elements $[16,17]$. Such structural elements may include layers made of structural steel, titanium, brass, aluminum, nickel, but also of non-metallic materials such as polyethylene, kevlar, glass fibers and carbon fibers. Elements of this type are most often used due to the improvement of thermal properties, chemical properties (e.g. corrosion resistance) as well as the mechanical parameters of the structure in which such elements are present. In the works [16, 17] an analytical solution was presented with the use of mathematical formulas enabling engineers to estimate the effort of the designed cladded perforated plates subjected to various types of load. It was found that both the finite element method and the analytical method make it possible to determine the stress values in plated perforated plates in the transition layers, i.e. in the transition layer on the titanium side and in the transition layer on the steel side. Experimental methods based on strain gauges do not offer such possibilities.

The presented work proposes an experimental approach to determining the stress values in a steel - titanium circular perforated plate, freely supported on the edge and loaded centrally with a concentrated force $P_{i}$ perpendicular to the plate surface. The research carried out at work was based on the use of resistance strain gauges. The results of the research presented in the paper can be used by engineers to design bimetallic perforated plates loaded perpendicular to their surface.

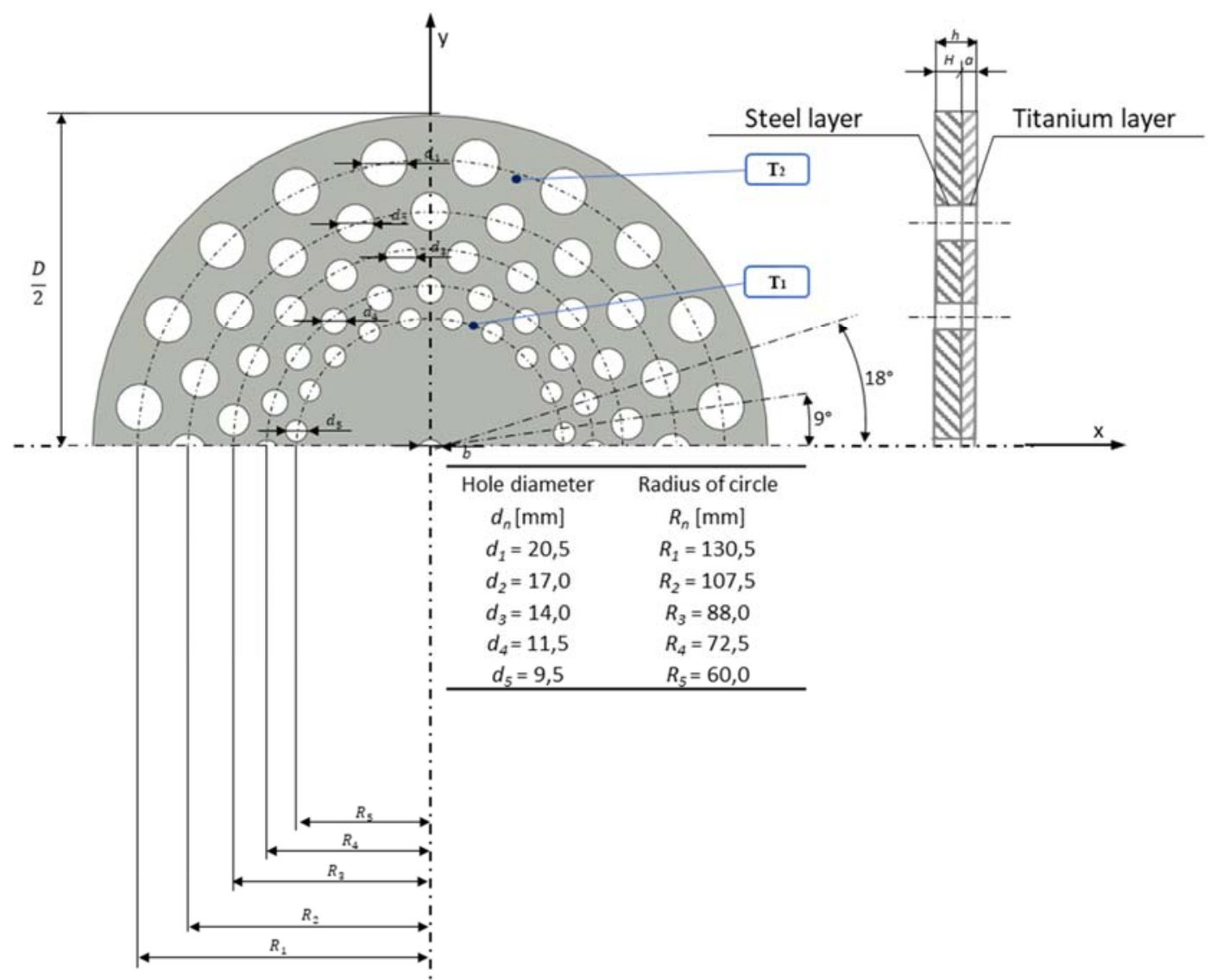

Figure 1: Model of bimetallic perforated plate consisting of steel thickness perforated plate $H$ and titanium perforated plate thickness $a$ containing holes with diameters $d_{1}, \ldots, d_{5}$. 


\section{SUBJECT OF THE RESEARCH}

7 he experimental research was based on a bimetallic circular axisymmetric perforated plate with dimensions: diameter $D=300 \mathrm{~mm}$ and comprising two layers, i.e. the base layer B in the form of structural steel with a thickness of $H=$

$10 \mathrm{~mm}$ and the applied layer (plating) in the form of titanium with the thickness of $a=2.5 \mathrm{~mm}$. 100 holes with different radii located on the plate. These holes were arranged in five circles with 20 holes in each circle. On the first outer circle, the plate had holes $d_{1}=20.5 \mathrm{~mm}$ in diameter and on the fifth, inner circle holes $d_{5}=9.5 \mathrm{~mm}$ in diameter. The scheme of the plate is shown in Fig. 1, and the plate in fact in Fig. 2. The perforated plate adopted for experimental research was made of a metallic composite called a platter, obtained during the so-called explosive plating. Explosive plating, also known as bonding or welding, consists in joining two or more metal elements with the use of energy released during the detonation of an explosive (Fig. 2) [18]. This technology is mainly used for materials that are difficult to join or cannot be joined by other methods. In this case, it was a steel sheet with a titanium layer applied to it. The plate prepared in this way was subjected to a rolling process to obtain a circular plate. Then, holes were drilled in the plate, positioned as shown in Fig. 1. The base material of the plate was steel sheet of the S355J2 grade, and the applied material was titanium sheet with the following mechanical and material parameters (Tab. 1) [19].

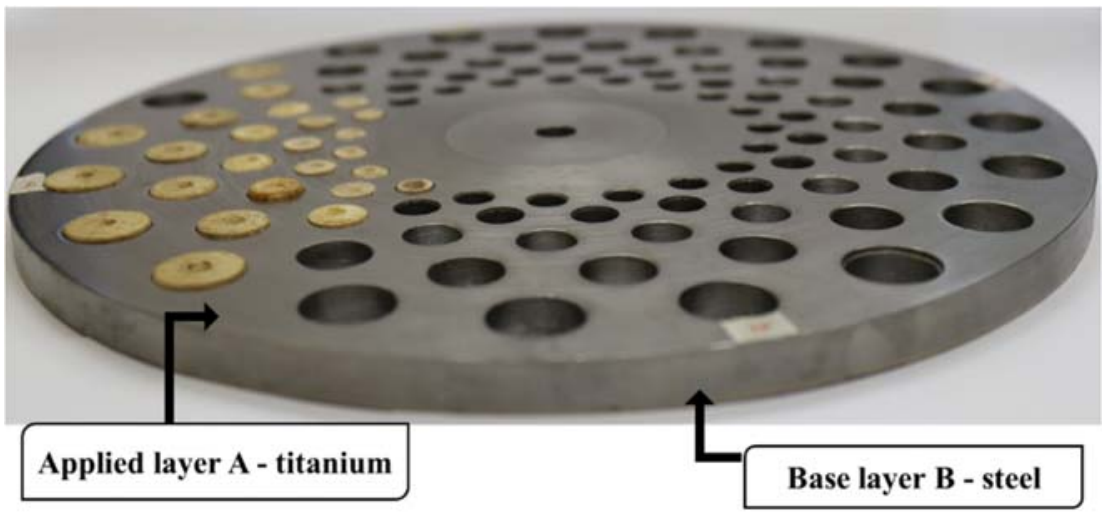

Figure 2: Model of bimetallic perforated plate.

\begin{tabular}{|c|c|c|c|c|c|c|}
\hline \multicolumn{7}{|c|}{ S355J2 steel and titanium } \\
\hline \multicolumn{7}{|c|}{ Applied layer A - titanium } \\
\hline$R_{e}[\mathrm{MPa}]$ & $R_{m}[\mathrm{MPa}]$ & $E[\mathrm{GPa}]$ & $\boldsymbol{v}[-]$ & $G[\mathrm{GPa}]$ & $A 5[\%]$ & \\
\hline $189-215$ & $308-324$ & 100 & 0.37 & 36.5 & $43-56$ & \\
\hline $\mathrm{C}$ & $\mathrm{Fe}$ & $\mathrm{H}$ & $\mathrm{N}$ & $\mathrm{O}$ & $\mathrm{Ti}$ & \\
\hline 0.10 & 0.20 & 0.015 & 0.03 & 0.18 & 99.5 & \\
\hline \multicolumn{7}{|c|}{ Base layer B - S355J2 steel } \\
\hline$R_{e}[\mathrm{MPa}]$ & $\mathrm{R}_{m}[\mathrm{MPa}]$ & $E$ [GPa] & $\boldsymbol{v}[-]$ & $G$ [GPa] & $A 5[\%]$ & \\
\hline $382-395$ & $598-605$ & 220 & 0,30 & 84,6 & 24-34 & \\
\hline C & $\mathrm{Si}$ & $\mathrm{Mn}$ & $\mathrm{P}$ & S & $\mathrm{Cu}$ & $\mathrm{Fe}$ \\
\hline 0.22 & 0.55 & 1.60 & 0.025 & 0.025 & 0.45 & all \\
\hline
\end{tabular}

Table 1: Strength properties and chemical composition of S355J2 steel and titanium, where: $R_{e}$ - yield strength [MPa], $R_{m}-$ tensile strength [MPa], E- Young's modulus [GPa], $\boldsymbol{v}$ - Poisson's ratio [-], A5 - tensile elongation [\%]. 


\section{RESEARCH METHOD}

$\mathrm{T}$

he aim of the experimental tests was to determine the state of stress in a steel - titanium circular perforated plate. This plate was loaded with a concentrated force $P_{i}$ applied in its geometric center perpendicular to its surface, and the boundary conditions were assumed in the form of free support of the plate on its edge. On a previously prepared steel - titanium perforated plate, Tokyo Sokkia Kenkyujo Co Ltd, FLA-1-11 strain gauges with a measuring base of $1 \mathrm{~mm}$ and a strain gauge constant $\mathrm{k}=2.14$ (Fig. 3) were attached, on two plate layers, i.e. on base layer B - steel and on the applied layer A - titanium at 20 measuring points on the bridges between the holes in the circumferential direction, i.e. from AC1 to $\mathrm{AC} 5$ and from $\mathrm{BC} 1$ to $\mathrm{BC} 5$, and in the radial direction, i.e. from AR1 to AR5 and from BR1 to BR5. This situation is illustrated in Figs. 4 and 5. Wooden pegs (Fig. 2), to which clamps are screwed, were placed in the appropriate holes of the experimental plate. In this way, the cables connecting the strain gauge with the measuring system of the Wheatstone bridge were immobilized and thus secured against breaking. As the plate is axially symmetrical with an axially-symmetrical distribution of holes (the hole spacing is 18 degrees), Fig. 5 show the actual arrangement of the strain gauges for a quarter of the plate.

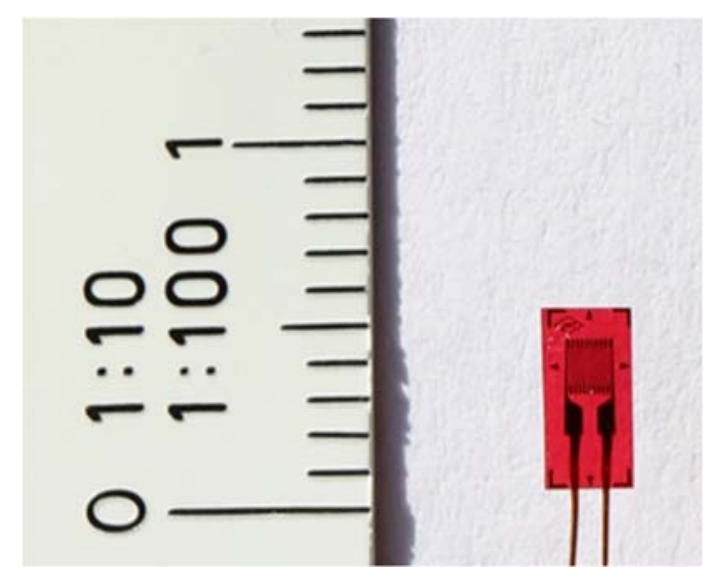

Figure 3: Strain gauges type: Tokyo Sokkia Kenkyujo Co Ltd, FLA-1-11.
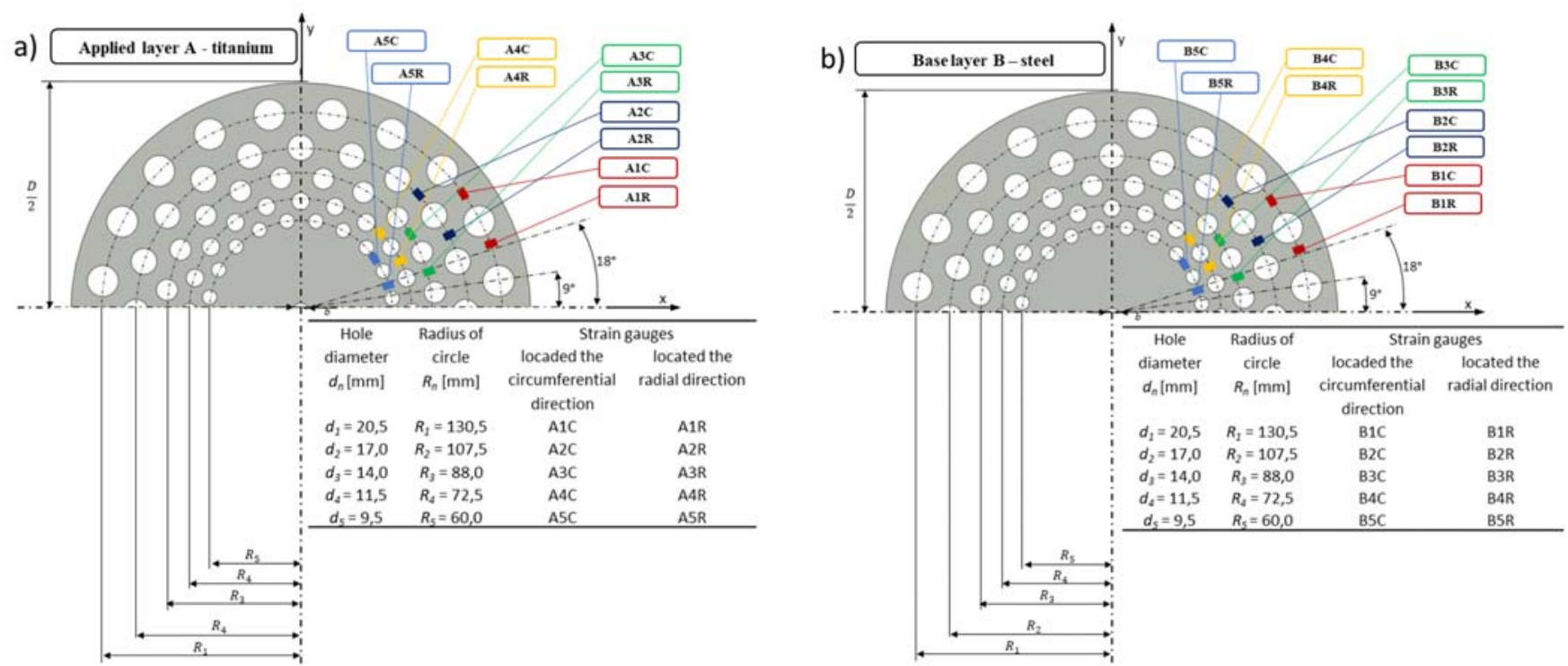

Figure 4: Arrangement of strain gauges on a bimetallic circular perforated plate: a) on the applied layer A - titanium; b) on the base layer B - steel (schematically). 
a)

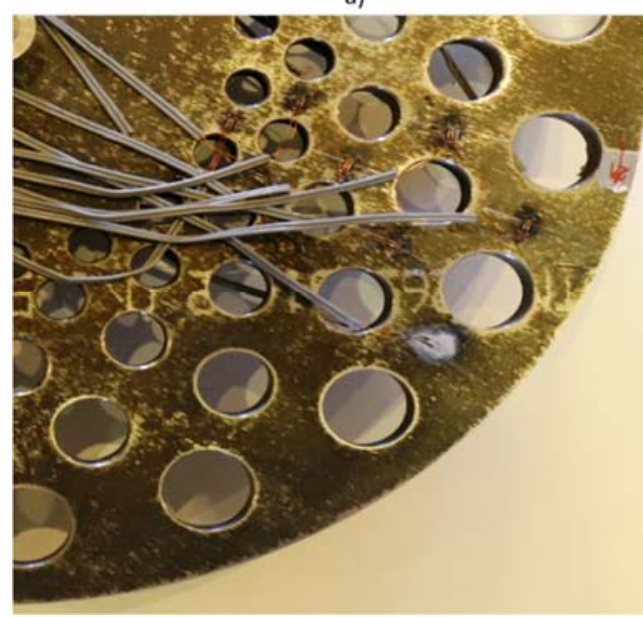

b)

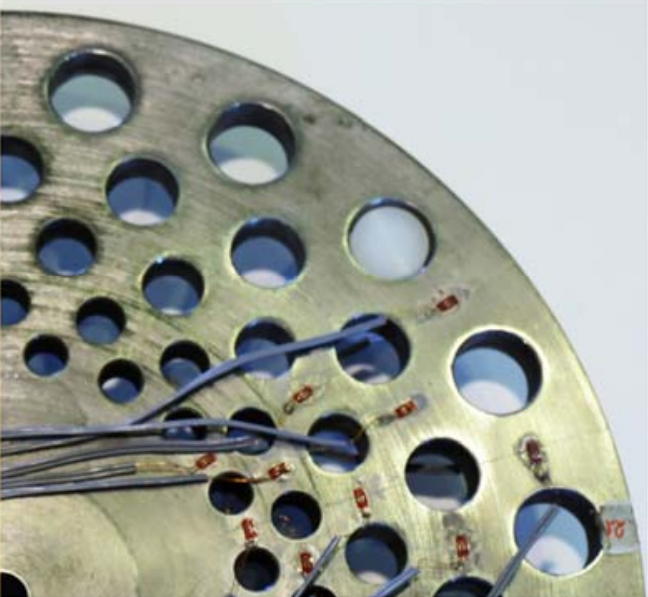

Figure 5: Arrangement of strain gauges on a bimetallic circular perforated plate: a) on the applied layer A - titanium; b) on the base layer $\mathrm{B}-$ steel (schematically).
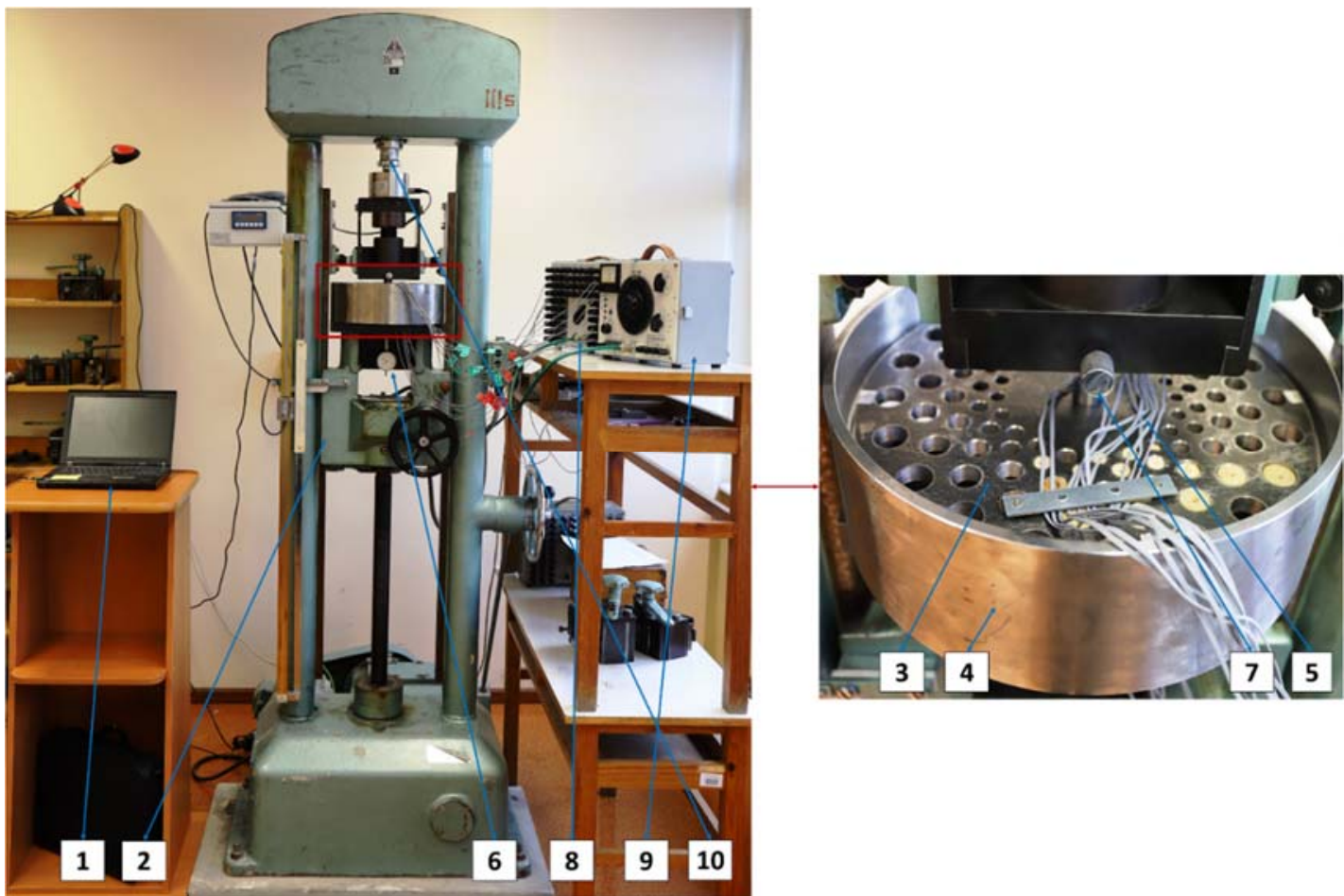

Figure 6: View of the testing machine prepared for testing in the case of plate loading with concentrated force P, where: 1 - computer, 2 - universal testing machine, 3 - steel-titanium circular axially symmetrical perforated plate, 4 - annular support, 5 - strain gauge, 6 sensor dial, 7 - pressure pin, 8 - distribution box, 9 - strain gauge bridge, 10 - dial gauge.

\section{RESEARCH POSITION}

A suitable test stand was prepared to measure the topography of deformations in a steel - titanium circular perforated plate. For this purpose, an appropriately designed annular support was made to ensure the boundary conditions of free support. The ZDM 10 universal testing machine from Werkstoff Preufmaschinnen Leipzig was used for the tests. The annular support was mounted on the machine in such a way that the axis of the loading pin passes through its axis of symmetry. The test plate with the strain gauges glued on was placed on the thus prepared support in such a way that the lower layer of the plate, i.e. the base layer B - steel, touched the support, while the upper layer, i.e. the layer A - titanium, 
was in contact with the mandrel of the testing machine. The experimental plate was loaded in the form of a concentrated force. This type of load was realized directly by the mandrel of the testing machine, which corresponds to a case of concentrated force $P_{i}$ applied at the geometric center of the plate normal to its surface. The test stand used for the experiment is shown in Fig. 6. The measurement of deformation in the plate was made with the use of a set consisting of a distribution box and a T2-type strain gauge bridge with a reading unit value of $0.005 \%$. However, the plate deflection was controlled with a dial gauge with an indication accuracy of $0.01 \mathrm{~mm}$ and a measuring range of $10 \mathrm{~mm}$. The dial indicator was attached to the annular support in such a way that the axis of the stylus passes through the center of the experimental plate and lies in the axis of the loading pin of the testing machine. After the experimental plate was properly placed on a specialized support, the axiality of the sensor's measuring pin and the loading pin of the testing machine was checked. After resetting the measuring devices, the test stand was ready for the experiment.

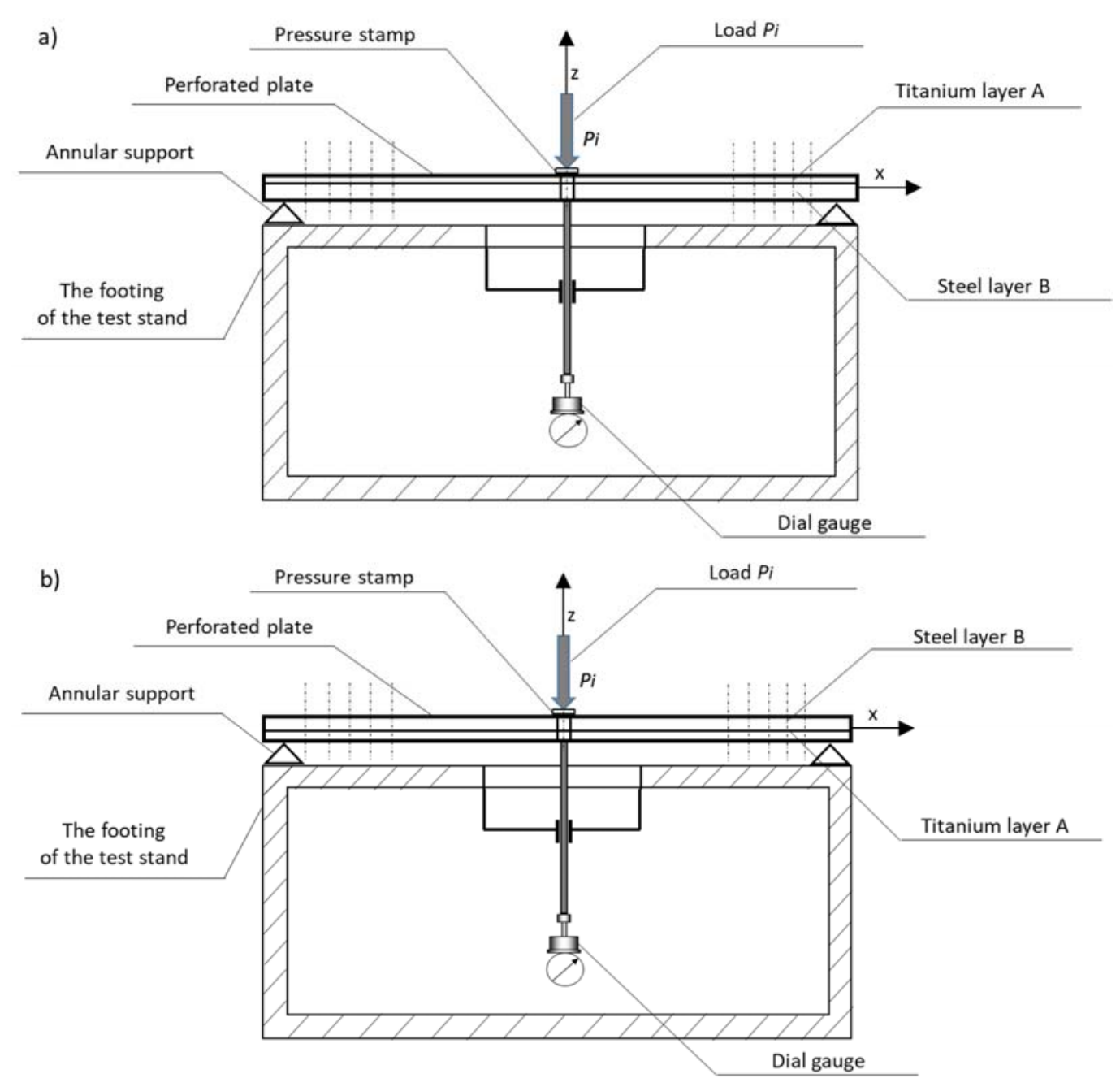

Figure 7: Scheme of a steel - titanium circular perforated plate mounted on a ring support and loaded with a concentrated force $P_{i}$ applied in the geometric center of the plate normally to its surface: a) from the layer of the applied plate A - titanium; b) from the side of the base layer of the B plate - steel, where: 1 - bimetallic circular perforated plate, 2 - the applied layer of the plate A - titanium, 3 base layer of the plate B - steel, 4 - annular support, 5 - stand support, 6 - $P_{i}$ load, 7 - dial gauge, 8 - pressure stamp.

\section{COURSE OF RESEARCH}

$\mathrm{I}$ $\mathrm{n}$ the first case, a steel - titanium circular perforated plate was loaded with a concentrated force $P_{i}$ applied in the geometric center of the plate perpendicularly to the surface of the applied A - titanium plate, and the boundary conditions were assumed in the form of free support of the plate on its edge. The diagram of fastening and loading of the perforated plate for the analyzed case is shown in Fig. 7a. In the second case, a steel - titanium circularsymmetrical 
perforated plate was loaded with a concentrated force $P_{i}$ applied in the geometric center of the plate perpendicularly to the base surface of the B - steel plate, and the boundary conditions were assumed in the form of free support of the plate on its edge. The diagram of fastening and loading of the perforated plate for the analyzed case is shown in Fig. 7b. Then, the plate was initially subjected to a load $P_{0}$ causing a deflection $w_{0}$ in its center. After obtaining the initial load and deflection, readings of strain gauges on each of the radial circles in the radial and circumferential directions were read and recorded as the initial reading marked with the index "p". Then the plate was loaded with the force $P_{i}$, which caused the deflection. The readings of the strain gauges were read again and marked with the index " $\mathrm{k}$ " as the final reading. A similar measurement procedure was used for the successive forces $P_{2}, P_{3}$ and $P_{4}$, which corresponded to the deflections $w_{2}$, $w_{3}$ and $w_{4}$. The following values of the $P_{i}$ load were adopted: $P_{1}=5 \mathrm{kN}, P_{2}=10 \mathrm{kN}, P_{3}=15 \mathrm{kN}, P_{4}=20 \mathrm{kN}$. The readings of strain gauges during measurements and the strains calculated on their basis in the circumferential direction $\varepsilon_{\theta}$ and in the radial direction $\varepsilon_{r}$ were used to determine the appropriate stresses.

\section{RESEARCH RESULTS AND THEIR ANALYSIS}

$\mathrm{I}$

$\mathrm{t}$ was assumed that a plane state of stress occurs in a steel - titanium circular perforated plate. For the elastic state of strains, the relationships between strains and stresses result from the generalized Hooke's law. If the principal directions 1 and 2 are known, the relationship between the strains $\varepsilon_{1}$ and $\varepsilon_{2}$, and the stresses $\sigma_{1}$ and $\sigma_{2}$, takes the following form [20]:

$$
\begin{aligned}
& \sigma_{1}=\frac{E}{1-v^{2}}\left(\varepsilon_{1}+v \varepsilon_{2}\right) \\
& \sigma_{2}=\frac{E}{1-v^{2}}\left(\varepsilon_{2}+v \varepsilon_{1}\right)
\end{aligned}
$$

where:

$E$ - Young's modulus [MPa];

$v$ - Poisson's ratio [-].

In our case, the main directions of the axially symmetrical perforated plate are radial direction $r$ and circumferential direction $\theta$. Therefore, having determined the deformations in the radial direction $\varepsilon_{r}$ and in the circumferential direction $\varepsilon_{\theta}$, the main stress components in the radial direction $\sigma_{r}$ and in the circumferential direction $\sigma_{\theta}$ were determined from the following relationships:

$$
\begin{gathered}
\sigma_{r}=\frac{E}{1-v^{2}}\left(\varepsilon_{r}+v \varepsilon_{\theta}\right) \\
\sigma_{\theta}=\frac{E}{1-v^{2}}\left(\varepsilon_{\theta}+v \varepsilon_{r}\right)
\end{gathered}
$$

After determining the radial stress values $\sigma_{\mathrm{r}}$ and circumferential stresses values $\sigma_{\theta}$, these values were introduced into the formula for equivalent von Mises stress $\sigma_{\text {red }}$, in the form:

$$
\sigma_{r e d}=\sqrt{\sigma_{r}^{2}+\sigma_{\theta}^{2}-\sigma_{r} \sigma_{\theta}}
$$

Figs. 8 and 9 shown the values of stresses in the radial direction $\sigma_{r}$ and circumferential direction $\sigma_{\theta}$ and equivalent von Mises stress $\sigma_{r e d}$ at the designated measurement points of the plate on the surface of the applied layer of the plate A titanium (Fig. 4a and 5a) and on the surface of the base layer of the plate B - steel (Fig. 3b and 4b) with different loading forces, i.e. $P_{1}=5 \mathrm{kN}, P_{2}=10 \mathrm{kN}, P_{3}=15 \mathrm{kN}, P_{4}=20 \mathrm{kN}$. In this case, the load was applied from the side of the titanium layer as shown in Fig. 7a. Figs. 10 and 11 shown the values of stresses in the radial direction $\sigma_{r}$ and circumferential direction 
$\sigma_{\theta}$ and the equivalent von Mises stress $\sigma_{r e d}$ at the designated measurement points of the plate on the surface of the applied layer of the plate A - titanium (Fig. $4 \mathrm{a}$ and $5 \mathrm{a}$ ) and on the surface of the base layer of the plate B - steel (Fig. 4b and 5b) with different loading forces, i.e. $P_{1}=5 \mathrm{kN}, P_{2}=10 \mathrm{kN}, P_{3}=15 \mathrm{kN}, P_{4}=20 \mathrm{kN}$. In this case, the load was applied from the side of the steel layer, as shown in Fig. $7 \mathrm{~b}$.

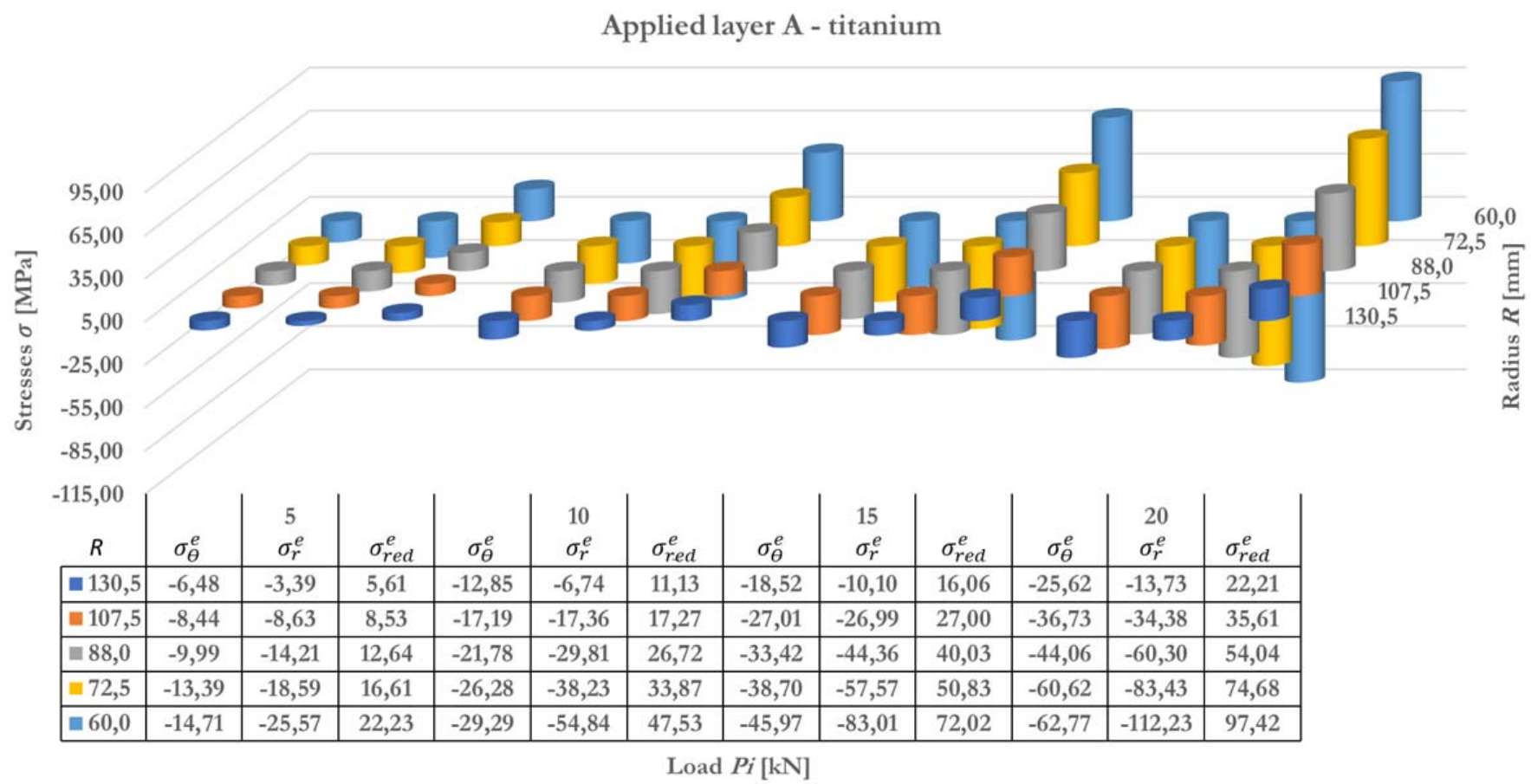

Figure 8: Summary of the stress values, respectively: $\sigma_{\theta}, \sigma_{r} \sigma_{r e d}$ determined on the surface of the applied layer of the plate A titanium, in this case, the load was applied from the side of the titanium layer.

\section{Base layer B - steel}

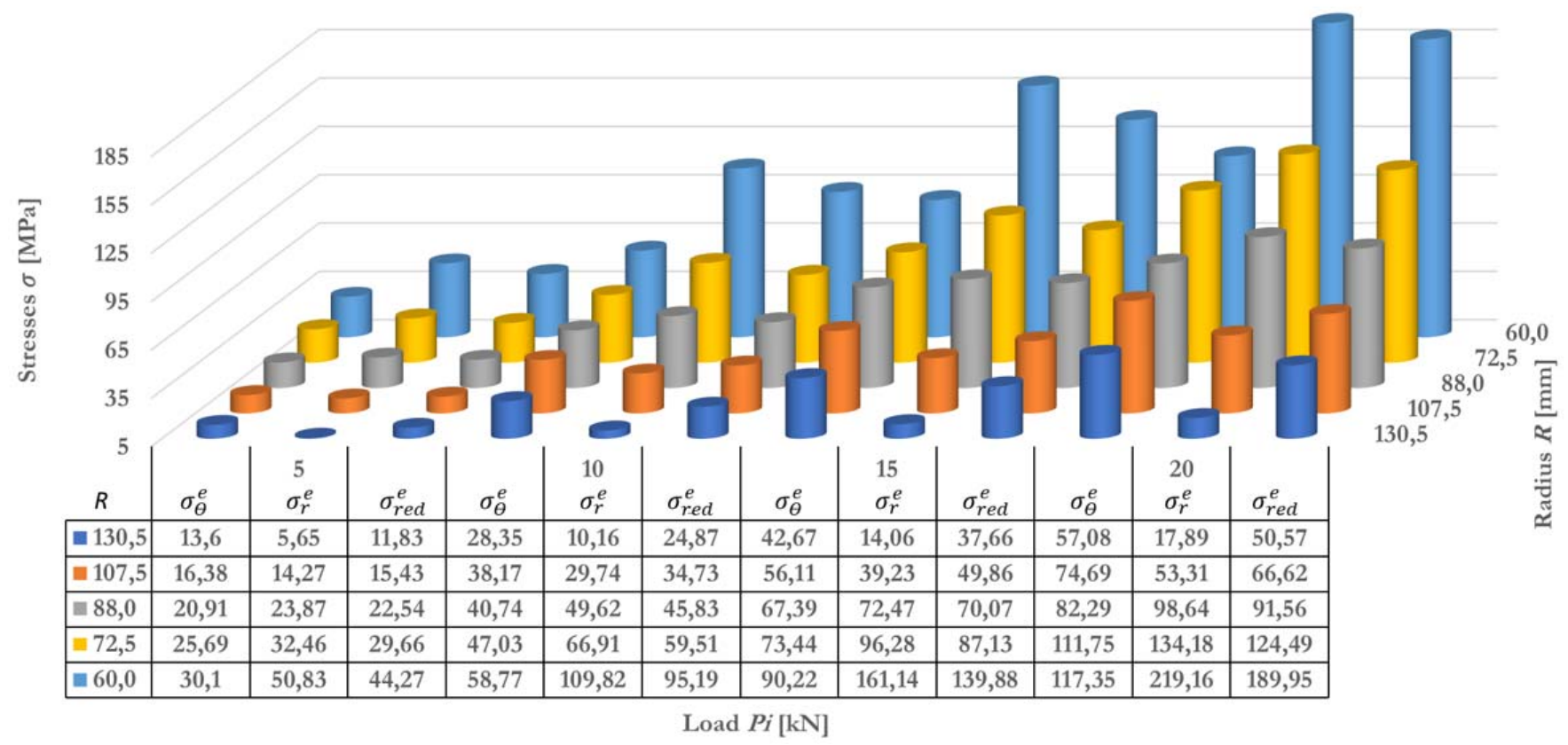

Figure 9: Summary of the stress values, respectively: $\sigma_{\theta}, \sigma_{r} \sigma_{r e d}$ determined on the surface of the base layer of the plate B - steel., in this case, the load was applied from the side of the steel layer. 


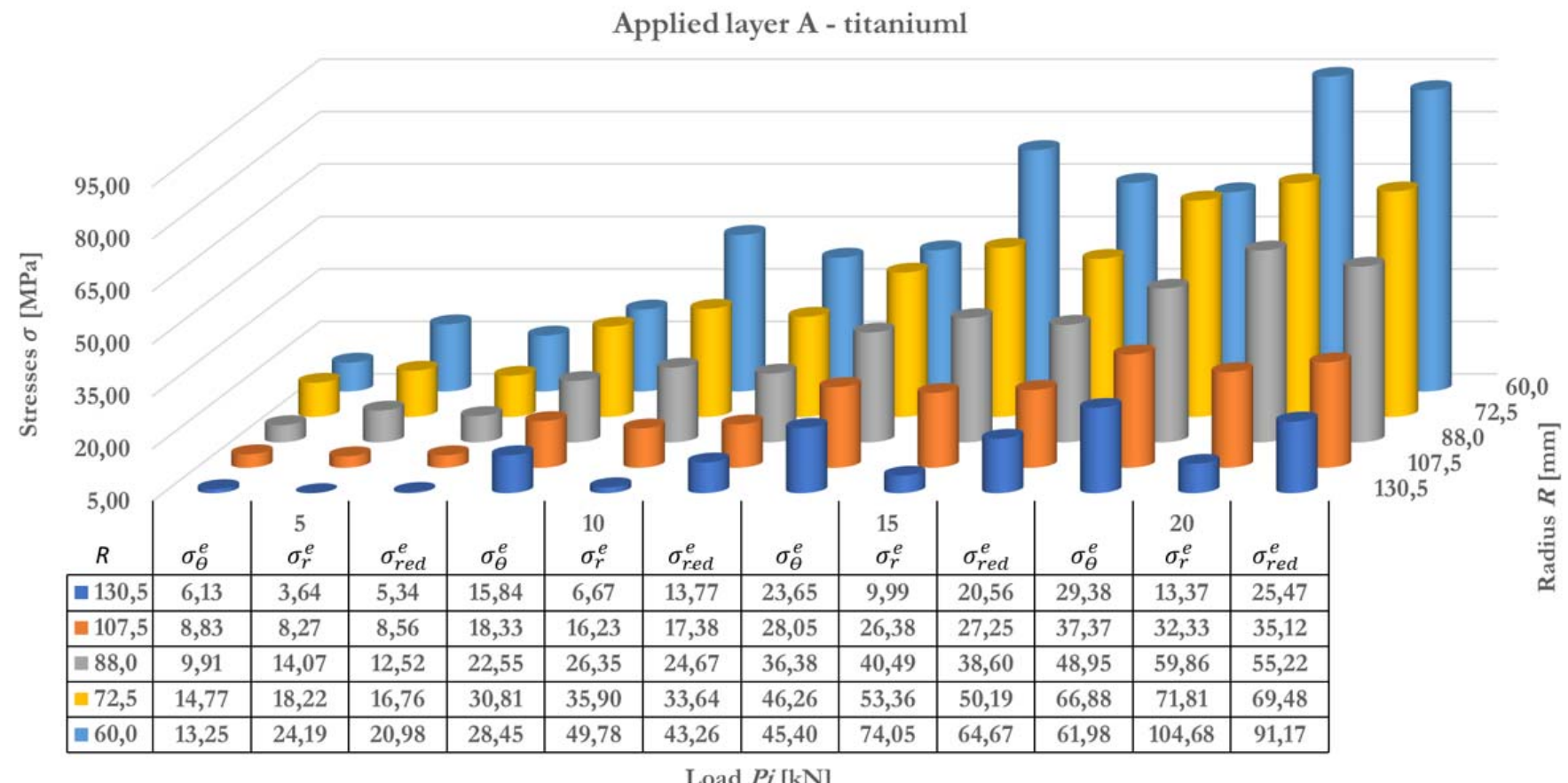

Figure 10: Summary of the stress values, respectively: $\sigma_{\theta}, \sigma_{r} \sigma_{r e d}$ determined on the surface of the applied layer of the plate A titanium, in this case, the load was applied from the side of the titanium layer.

Base layer B - steel

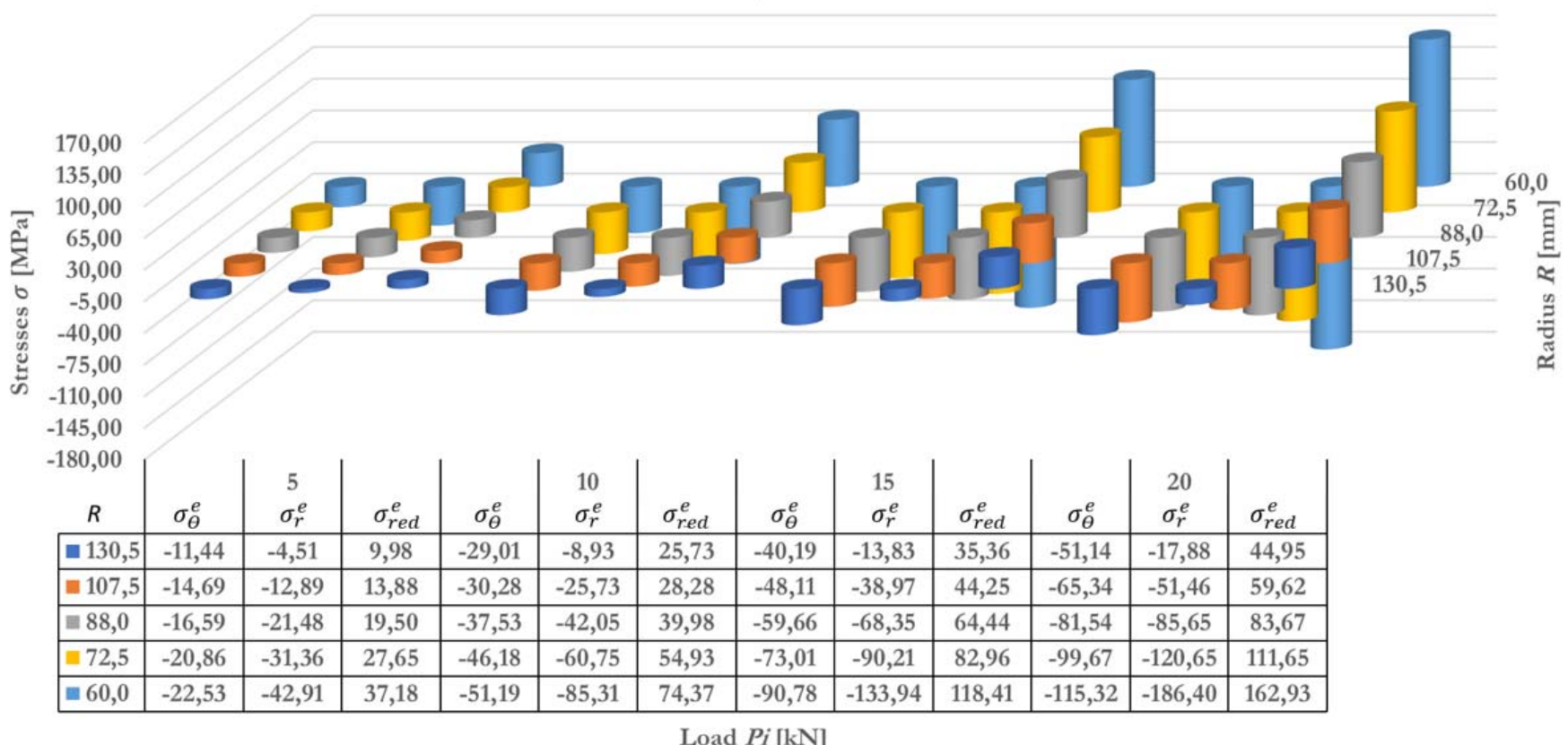

Figure 11: Summary of the stress values, respectively: $\sigma_{\theta}, \sigma_{r} \sigma_{r e d}$ determined on the surface of the base layer of the plate B - steel, in this case, the load was applied from the side of the steel layer.

Fig. 12 shows the results of measurements of deflection $w$ for a steel - titanium circular perforated plate, freely supported and loaded with a concentrated force $P_{i}$ applied in the geometric center of the plate, determined experimentally in its 
geometric center, in the case where the load was applied from the side of the titanium layer $-w_{1}$ and if the load was applied from the steel layer $-w_{2}$.

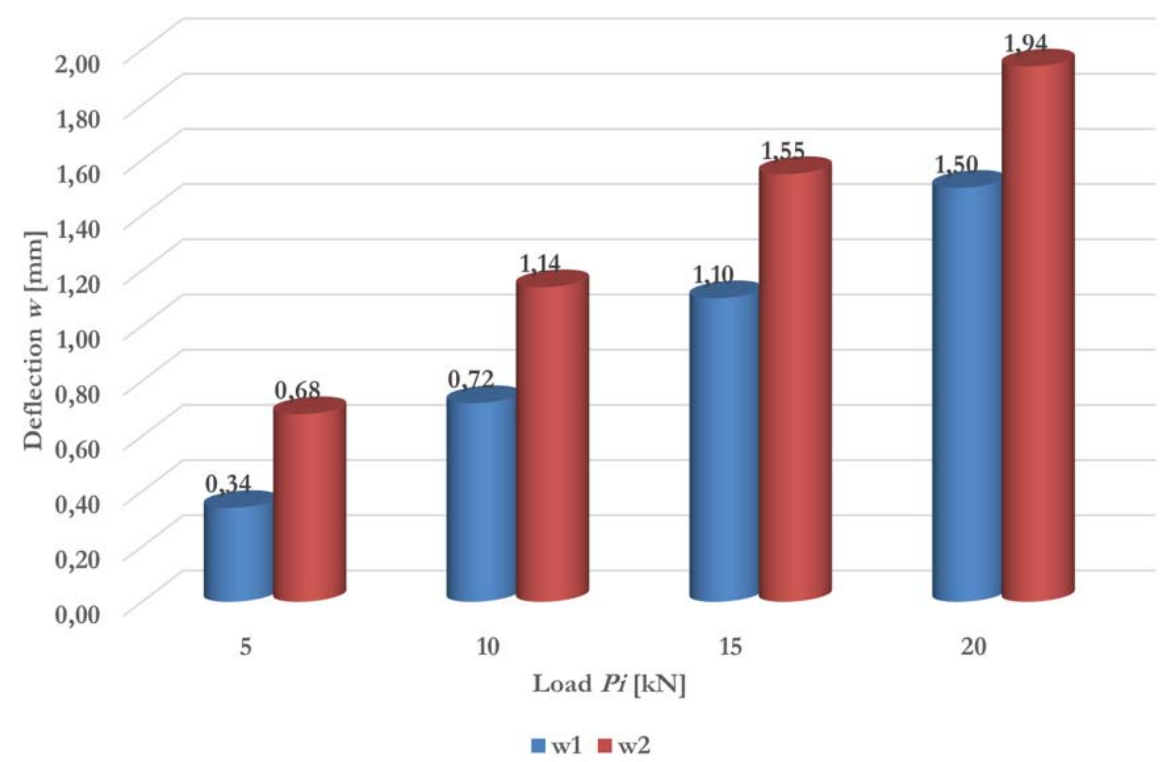

Figure 12: Results of measurements of deflection in the center of the slab, at various loads with concentrated force Pi in the geometric center of the slab, normal to its surface, where: $w_{1}-$ the load was applied from the side of the titanium layer, $w_{2}-$ the load was applied from the side of the steel layer.

Figs. 8 - 11 summarize the stress values in a bimetallic perforated plate centrally loaded with a concentrated force $P_{i}$. The strains measurement concerned points on the bridges between the plate holes, arranged according to the diagrams shown in Figs. 4 and 5. These are points in zones with a significant stress concentration compared to a homogeneous plate.

The comparison of the stress results presented in Figs. 8-11 shows that when the plate load is applied from the side of the applied layer, i.e. the titanium, stress values differ slightly from the stresses obtained for the same plate but loaded from the side of the base layer, i.e. steel. This is the result of residual stresses in the bimetallic perforated plate. In practice, such bimetallic plates are not subject to heat treatment due to their large size. In industry, such plates are used in the raw state [19], for example as heat exchanger tube sheets [10].

The deformation measurements were made in the plate perforation zone (Figs. 4 and 5), where in the process of making holes, the residual stresses should be reduced. However, the conducted tests showed that the residual stresses cause discrepancies in the determination of stresses resulting from the load on the perforated plate. Moreover, it can be seen from Fig. 12 that when the load is applied from the side of the base layer, i.e. the steel layer, the deflection $w_{1}$ is greater than the deflection obtained when the load was applied from the side of the applied layer, i.e. the titanium layer $w_{2}$. It also indicates that residual stresses occur in the bimetallic perforated plate in the area where the titanium plates are connected to the steel plate [21]. The deflection concerns the point of the geometric center of the plate, which consists of a perforated zone $(60$ $\mathrm{mm} \leqslant r \leqslant 130.5 \mathrm{~mm})$ and a homogeneous zone $(6 \mathrm{~mm} \leqslant r \leqslant 60 \mathrm{~mm})$ (Fig. 1).

\section{CONCLUSIONS}

he following conclusions can be drawn from the above analysis:

1) The distribution of stresses in the plate perforation zone was determined in the places of stress concentration;

2) It has been shown that despite the holes made in the plate, we deal with the presence of residual stresses arising in the process of explosive joining of steel sheet with titanium sheet; 
3) The proposed method of experimental research can be used by engineers to verify the state of stress, e.g. in the designed tube sheet walls of reactors for ammonia synthesis.

\section{REFERENCES}

[1] Niezgodziński, M.E. (1973). Obliczenia grubości ścian sitowych w zbiornikach ciśnieniowych, Przegląd Mechaniczny, 3, ss. 102-105 (in Polish).

[2] Chen, K.T., Ting, K. and Yang, W.S. (2000). Stress analysis of two-dimensional perforated plates using boundary element alternating method, Computers and Structures, 75, pp. 515 - 527, DOI: 10.1016/S0045-7949(99)00103-0.

[3] Kang, J. H. (2014). Exact solutions of stresses, strains, and displacements of a perforated rectangular plate by a central circular hole subjected to linearly varying inplane normal stresses on two opposite edges, International Journal of Mechanical Sciences, 84, pp. 18 - 24, DOI: 10.1016/j.ijmecsci.2014.03.023.

[4] Mirji, P. (2013). Optimization of rectangular plate with two holes subjected to in plane static loading, International Journal of Scientific and Engineering Research, 4(6), pp. 1470 - 1473.

[5] Bhattacharya, A. and Venkat, R. (2003). Peak stress multipliers for thin perforated plates with square arrays of circular hole, International Journal Pressure Vessels and Piping, 80, pp. 379 - 388, DOI: 10.1016/S0308-0161(03)00067-X.

[6] Bhattacharya, A. and Venkat, R. (2004). Yield Surfaces for Perforated Plates with Square Arrays of Holes, Nuclear Engineering and Design, 231, pp. 219 - 233, DOI: 10.1016/j.nucengdes.2004.04.001.

[7] Niezgodziński, M.E. and Zwoliński, W. (1973). Obliczenie den sitowych usztywnionych przez płaszcz zbiornika, Przegląd Mechaniczny, 8, (in Polish).

[8] Konieczny, M., Achtelik, H. and Gasiak, G. (2020). Finite Element Analysis (FEA) and experimental stress analysis in circular perforated plates loaded with concentrated force, Frattura ed Integrità Strutturale, 51, pp. 164-173, DOI: 10.3221/IGF-ESIS.51.13.

[9] Achtelik, H., Gasiak, G.and Grzelak, J. (2008). Strength tests of axially symmetric perforated plates for chemical reactors: Part 1-The simulation of stress state, International Journal of Pressure Vessels and Piping, 85, pp. 248 - 256, DOI: 10.1016/j.ijpvp.2007.08.009.

[10] Achtelik, H., Gasiak, G. and Grzelak, J. (2008). Strength tests of axially symmetric perforated plates for chemical reactors: Part 2-Experiments, International Journal of Pressure Vessels and Piping, 85, pp. 257 - 264, DOI: $10.1016 /$ j.ijpvp.2007.08.010.

[11] Ledwon ,W. and Achtelik, H. (2017). Experimental analysis of the state of stress of the axisymetric perforated plates loaded with hydrostatic pressure, Proceedings of the $13^{\text {th }}$ International Scientific Conference: Computer Aided Engineering, pp. 331 - 341.

[12] Duncan, J. P. (1955). The structural efficiency of tube - plates for head exchangers, Proceedings of Institute of Mechanical Engineers, 169, pp. 789-802.

[13] Gasiak, G. and Sojka, M. (2005). Wytężenie płyt perforowanych, Studia i Monografie, 224, Politechnika Opolska, ss. 95 -108 (in Polish).

[14] Andh, U., Chavan, S., Kulkarni, S. and Khurd, S. (2016). Stress analysis of perforated plates under uniaxial compression using FEA and photoelasticity, International Research Journal of Engineering and Technology, 3 (11), pp. 239 - 244, DOI: 10.1007/978-3-030-16848-3_90.

[15] Andh, U., Chavan, S., Kulkarni, S. and Khurd, S. (2017). Stress analysis of perforated plates under uniaxial compression using experimentation and finite element analysis, International Journal of Current Engineering and Technology, 7(2), pp. $431-437$.

[16] Konieczny, M., Achtelik, H. and Gasiak, G. (2020). Stress distribution in plated perforated plate loaded centrally with concentrated force, Zmęczenie materiału w eksploatacji maszyn roboczych, PO, 2, pp. 47-62.

[17] Konieczny, M., Achtelik, H. and Gasiak, G. (2021). Location of stress concentration zones in a two-layer axially symmetrical perforated plate with force applied normally to its surface, Engineering Structures, 226, pp. 1-14.

[18] Walczak, W. (1989). Metal explosion welding, WTN, Warsaw (in Polish).

[19] Data from Explomet Company research (Z.T.W. EXPLOMET, Gałka, Szulc, Sp. j. ul. Oświęcimska 100H, 45-641 Opole, Poland).

[20] Thimoshenko, S. Strengh of Materials, Princeton D. Van Nostrand Co, Inc. Part 1 (1956), Part 2 (1957).

[21] Karolczuk, A. and Kowalski, M. (2013). Residual stress determination based on the hole drilling method in explosively welded bimetallic composite, $13^{\text {th }}$ International Conference on Material Modelling, Warsaw, p. 140. 